\title{
Exposure to $\Delta$-9-Tetrahydrocannabinol (THC) Increases Subsequent Heroin Taking but not Heroin's Reinforcing Efficacy: A Self-Administration Study in Rats
}

\author{
M Solinas', LV Panlilio' and SR Goldberg*,I \\ 'Preclinical Pharmacology Section, Behavioral Neuroscience Branch, Department of Health and Human Services, Baltimore, MD, USA
}

\begin{abstract}
One concern about the widespread use of cannabis is that exposure to its active ingredient, $\Delta$-9-tetrahydrocannabinol (THC), might increase future reinforcing effects of other abused drugs such as heroin. In this study, we investigated the effects of pre-exposure to THC on subsequent intravenous self-administration of heroin by Sprague-Dawley rats. In one group of rats, we studied (I) acquisition of heroin self-administration behavior using a continuous-reinforcement (fixed-ratio (FR) I) schedule, (2) heroin dose-response relationships using an FRI/variable-dose schedule, and (3) reinforcing efficacy of heroin using a progressive-ratio schedule. The number of rats pre-exposed to THC that subsequently learned to self-administer $50 \mu \mathrm{g} / \mathrm{kg}$ injections of heroin within 10 daily sessions did not differ from vehicle-pretreated controls. In contrast, rats pre-exposed to THC subsequently self-administered significantly more heroin injections per session and showed significantly shorter post-injection pauses over a range of heroin doses ( $12.5-100 \mu \mathrm{g} / \mathrm{kg} / \mathrm{injection}) \mathrm{using}$ the variable-dose schedule. Interestingly, the maximum effort rats would exert to receive an injection of the different doses of heroin under the progressive-ratio schedule was not altered by THC pre-exposure. In a second group of rats, we varied the 'price' of heroin (responses required/dose), by manipulating FR response requirements at different doses of heroin across sessions, to calculate demand and response output curves. Again, consumption was significantly higher in the THC-treated rats at the lowest prices of heroin (FRI/ $100 \mu \mathrm{g} / \mathrm{kg}$ and $\mathrm{FRI} / 50 \mu \mathrm{g} / \mathrm{kg}$ ) but there were no differences in the reinforcing efficacy of heroin between THC- and vehicle-pretreated rats. Altogether, these results demonstrate that pre-exposure to THC alters some pharmacological effects of heroin that determine frequency of heroin taking, but offer no support for the hypothesis that pre-exposure to THC alters heroin's efficacy as a reinforcer. Neuropsychopharmacology (2004) 29, I 30 I- 13 II, advance online publication, 24 March 2004; doi: I 0. I038/sj.npp. I 30043 I
\end{abstract}

Keywords: cannabinoids; THC; cannabis; opiates; gateway drug hypothesis; fixed-ratio schedule; behavioral economics; progressiveratio schedule

\section{INTRODUCTION}

Cannabis use is widespread among young people in the United States and Europe (Bachman et al, 1998; Reid et al, 2000). Although cannabis possesses addictive properties, there is a continuing debate on the possibility of legalizing cannabis use for medical purposes and decriminalizing its recreational use. One of the arguments used against legalization and decriminalization is that cannabis use could increase the probability of encountering, trying, and eventually becoming addicted to other illicit drugs such as heroin. This hypothesis, generally referred to as the

*Correspondence: SR Goldberg, Behavioral Pharmacology Section, Behavioral Neuroscience Research Branch, National Institute on Drug Abuse, Division of Intramural Research, National Institute of Health, 5500 Nathan Shock Drive, Baltimore, MD 21224, USA, Tel: + 1410 550 1522, Fax: + | 4105501648 ,

E-mail: sgoldber@intra.nida.nih.gov

Received 30 May 2003; revised 05 February 2004; accepted 06 February 2004

Online publication: 16 February 2004 at http://www.acnp.org/citations/ Npp02160403336/default.pdf 'gateway drug' hypothesis (Kandel et al, 1992), is strengthened by studies in humans showing that addiction to drugs is generally preceded by cannabis use. For example, Lynskey et al (2003) found that, even when different social and personality traits are taken into account, the correlation between cannabis use and escalation of use of other illicit drugs remains strong. However, causal relationships between drug exposure and subsequent addiction are difficult to establish in humans because of the many historical, environmental, and social variables that cannot be controlled.

It has been suggested that 'one of the best strategies to test the gateway hypothesis may be the use of animal models' (Kandel, 2003). In studies using animal models, variables such as behavioral and social history and previous exposure to drugs can be isolated or controlled, allowing one to study the effects of THC pre-exposure on subsequent responsiveness to other addictive drugs. In recent studies with rats, for example, it has been shown that exposure to cannabinoid CB1 receptor agonists produces long-lasting changes that result in increased responsiveness to the motor-activating effects not only of cannabinoid agonists (sensitization) 
(Cadoni et al, 2001; Rubino et al, 2001, 2003), but also of opioid agonists (cross-sensitization) (Cadoni et al, 2001; Lamarque et al, 2001; Pontieri et al, 2001; Norwood et al, 2003). Although these studies demonstrate an interaction between cannabinoid and opioid systems, studies on behavioral sensitization provide no direct information about the effects of cannabinoid exposure on subsequent responsiveness to the reinforcing properties of other drugs.

One way to investigate changes in the reinforcing efficacy of heroin after exposure to THC is to study the acquisition of heroin self-administration behavior. If heroin becomes more effective as a reinforcer after THC exposure, more rats would be expected to acquire heroin self-administration behavior. Another way to assess changes in the reinforcing efficacy of heroin is to measure the maximal effort an animal will exert to receive an injection of different doses of heroin using progressive-ratio schedules. A third way is to apply a behavioral economics framework (see Bickel et al, 2000 for a review) to the analysis of self-administration data and to calculate heroin 'demand curves' and 'response output curves' after exposure to THC or vehicle in order to describe behavior and heroin consumption when the 'price' of heroin (response requirement divided by dose) is varied. This analysis provides two measures: $P_{\max }$, a measure of how quickly consumption decreases as the price of heroin is increased; and $O_{\max }$, the maximum amount of behavior that heroin can maintain (see Hursh, 1991; Hursh and Winger, 1995). These behavioral economics measures appear to be analogous to the progressive-ratio measure of break point, since they all attempt to measure the maximum effort that will be expended to obtain a drug for consumption (Rodefer and Carroll, 1997).

In this study, we examined the effects of pre-exposure to THC on the acquisition of self-administration behavior for intravenous (i.v.) injections of $50 \mu \mathrm{g} / \mathrm{kg}$ doses of heroin, using a schedule of drug injection where operant responses by rats were continuously reinforced (a one-response fixedratio schedule, FR1). We then utilized an FR1/variable-dose schedule to investigate responses to different i.v. doses of heroin in these rats. Subsequently, we utilized a progressiveratio schedule to measure the maximal number of responses that rats would emit to self-administer a given dose of heroin by increasing the FR response requirement in steps within a session until responding ceased. In additional rats pre-exposed to either THC or vehicle before acquisition of heroin self-administration, we manipulated the price of heroin injections by varying both the FR response requirement and the dose per injection in different sessions. This allowed us to calculate and compare demand curves, describing the relationships between price and consumption of heroin, and response output curves, describing the relationship between price and responding, in rats preexposed to either THC or saline vehicle.

\section{MATERIALS AND METHODS}

\section{Subjects}

Sprague-Dawley rats (Charles River, Wilmington, MA, USA), experimentally naive at the start of the study and initially weighing 300-325 g, were used. Rats were housed two per cage until catheterization, then housed individually in a temperature- and humidity-controlled room and were maintained on a 12-h light/dark cycle. The lights were on from 0645 to 1845 and experiments were conducted during the light phase. Animals were maintained in facilities fully accredited by the American Association for the Assessment and Accreditation of Laboratory Animal Care; all experimentation was conducted in accordance with the guidelines of the Institutional Care and Use Committee of the Intramural Research Program, National Institute on Drug Abuse (NIDA), National Institutes of Health, the directives of the Principles of Laboratory Animal Care (National Institutes of Health publication number 85-23, revised 1985).

Rats had free access to food until 1 day before the start of self-administration sessions. At that time, food was restricted to approximately $15-20 \mathrm{~g}$ per day. This amount of food maintained rats' weights at an approximately constant level throughout the experiment. Water was available ad libitum for all animals.

\section{THC Pre-Exposure}

At 1 week after their arrival, rats in both Experiments one and two were randomly divided into two groups. One group received intraperitoneal (i.p.) injections of THC twice a day for 3 days. The dose of THC was $2 \mathrm{mg} / \mathrm{kg}$ on the first day, $4 \mathrm{mg} / \mathrm{kg}$ on the second day, and $8 \mathrm{mg} / \mathrm{kg}$ on the third day. The other group received an injection of an equivalent volume of the THC vehicle. This level of THC exposure has been shown to produce behavioral sensitization (motor activity) to THC and cross-sensitization to morphine (Cadoni et al, 2001).

\section{Catheterization}

At 1 day after the last i.p. THC or vehicle injection, catheters were implanted in the right jugular vein under aseptic conditions using i.p. ketamine $(60 \mathrm{mg} / \mathrm{kg})$ and xylazine $(10 \mathrm{mg} / \mathrm{kg})$ anesthesia as previously described (Solinas et al, 2003). When rats developed a blocked catheter in an advanced phase of the experiment, a second catheter was implanted in the left jugular vein as described above. During experimental sessions, the catheter was connected to an injection pump (Med Associates, St Albans, VT, USA) that delivered fluid from a $10-\mathrm{ml}$ syringe at a rate of $3.19 \mathrm{ml} /$ min through tubing passing through a metal spring that was attached to a plastic bolt on the rat's head. Catheters were flushed before and after each session with $0.1 \mathrm{ml}$ of saline solution.

\section{Heroin Self-Administration Apparatus}

Experimental chambers $(30 \times 24 \times 29 \mathrm{~cm}$, Coulbourn Instruments, Allentown, PA, USA) enclosed in soundattenuation chests, had a metal grid floor and two nosepoke holes in the right wall. Illumination was provided by a shielded white light at all times except during injection and time-out periods, when both an acoustic tone and the house light were pulsed at a rate of $5 \mathrm{~Hz}$, with one stimulus on while the other was off. Experimental events were controlled 
by microcomputers using Med Associates interfaces and software (Med Associates Inc., East Fairfield, VT, USA).

\section{Heroin Self-Administration Procedure}

\section{Experiment one.}

Heroin self-administration under an FR1 schedule: A total of 26 male rats were used in this experiment. Selfadministration sessions began 1 week after the last i.p. THC or vehicle injection, using an FR1 schedule of i.v. heroin injection and a heroin injection dose of $50 \mu \mathrm{g} / \mathrm{kg}$. During 3-h daily sessions, a single response in the left nose-poke hole (the active hole) immediately activated the injection pump and caused the house light to flash and a tone to pulse for $5 \mathrm{~s}$. During this 5-s time-out period, responding had no programmed consequences. Following each time-out, the next response in the left hole was again reinforced by an i.v. injection of $50 \mu \mathrm{g} / \mathrm{kg}$ of heroin. Responses in the nose-poke hole on the right side (the inactive hole) were recorded but had no programmed consequence. Acquisition of selfadministration behavior was evaluated over 10 consecutive sessions. Heroin self-administration behavior was considered acquired if rats obtained at least 10 heroin injections in each of the last three sessions. After the acquisition phase, rats were switched to an FR1/variable-dose schedule for two sessions, then to a progressive-ratio schedule for a total of 11 sessions and, finally, switched back to the simple FR1 schedule for the last three sessions. Three measures were collected in this phase of Experiment one: number of injections and number of nose-pokes in the active hole, including both reinforced and nonreinforced (during injections or time-out periods) nose-pokes. Self-administration behavior on the last day of self-administration was further analyzed. The time between each injection of heroin (post-injection pause or interinjection interval) was recorded in order to determine whether THC exposure determined differences in the pattern, or rate, of responding.

Heroin self-administration under an FR1/variable-dose schedule: After 10 days of heroin self-administration under the FR1 schedule, rats that had acquired self-administration behavior were switched to an FR1/variable-dose schedule of i.v. drug injection. Under this schedule, injection doses were manipulated by varying the duration of syringe-pump activation (approximately $0.5-2 \mathrm{~s}$ ). Each time an injection was delivered, the cue-light and tone were pulsed $(5 \mathrm{~Hz})$ for $5 \mathrm{~s}$. During this 5-s time-out period, responding had no programmed consequences. Four different injection doses $(12.5,25,50$, and $100 \mu \mathrm{g} / \mathrm{kg})$ of heroin were made available in pseudo-random order, with a total of 34 injections available per session. After the first two injections, which were always $50 \mu \mathrm{g} / \mathrm{kg}$ and were not analyzed, the doses were arranged as four sets of eight injections. Within each set, doses were determined by sampling without replacement from a list in which each dose occurred twice. The primary datum was the amount of time between consecutive reinforced responses. This measure, also known as postreinforcement pause, is expected to be directly proportional to the drug dose under an FR1 schedule of drug injection. Thus, rats are expected to make their next response earlier after a low dose and later after a high dose of drug.
Heroin self-administration under a progressive-ratio schedule: After two sessions under the FR1/variable-dose schedule, rats were switched to the progressive-ratio schedule of drug injection. Under the progressive-ratio schedule of i.v. drug injection, the response requirement increased with each successive injection. The steps of the exponential progression were the same as those used by Roberts and Bennett (1993). As previously described (Solinas et al, 2003), sessions under the progressive-ratio schedule lasted $5 \mathrm{~h}$ or until $30 \mathrm{~min}$ passed without a response, which almost always occurred within less than $5 \mathrm{~h}$. The break point was defined as the step number of the last ratio completed before $30 \mathrm{~min}$ of nonresponse or at the end of the $5 \mathrm{~h}$. Rats were allowed to self-administer the $50 \mu \mathrm{g} / \mathrm{kg} /$ injection dose of heroin for three sessions to learn the increasing response requirement for subsequent injections. There were then two consecutive sessions at each of four different doses of heroin, performed in the following order: $25,25,12.5,12.5,100,100,50,50 \mu \mathrm{g} / \mathrm{kg} /$ injection. The average value from these two consecutive sessions was used for statistical analysis. Heroin intake was calculated as the number of injections taken in a session multiplied by the dose of drug per injection.

\section{Experiment two.}

Heroin consumption as a function of price under $F R$ schedules: A total of 31 male rats were used in this experiment. Self-administration sessions started 1 week after the last i.p. injection of THC or vehicle. Rats acquired heroin self-administration behavior under the FR1 schedule procedure described in Experiment one at the heroin dose of $50 \mu \mathrm{g} / \mathrm{kg} /$ injection. Rats that were slow to acquire selfadministration were given a few response-independent injections of heroin at the beginning of the first experimental sessions to prime responding. When stable self-administration responding was obtained (number of injections per session did not differ more than $10 \%$ for at least three consecutive sessions), manipulations of FR response requirements and heroin injection dose started. Four different FR response requirements were tested (FR1, 5,15 , and 30) and were presented for two consecutive sessions each in ascending order. The average values from these two consecutive sessions were used for statistical analysis. Under these schedules, the first active-hole nosepoke in a session resulted in one injection of heroin and each subsequent injection of heroin required one, five, 15, or 30 nose-pokes. When all four FR response requirements were tested at one dose of heroin, dose of heroin was changed and the procedure was repeated in the same order. Four different heroin doses were tested in the following order: $50,25,12.5$, and $100 \mu \mathrm{g} / \mathrm{kg} /$ injection. Heroin intake (consumption) was calculated as the number of injections taken in a session multiplied by the dose of drug per injection.

\section{Drugs}

$\Delta$-9-THC (National Institute on Drug Abuse, Baltimore, $\mathrm{MD}$, USA), $50 \mathrm{mg} / \mathrm{ml}$ in ethanol, was dissolved in a solution $40 \% \mathrm{w} / \mathrm{v}$ of cyclodextrin (RBI/SIGMA, Natick, MA, USA). THC was given i.p. in a volume of $2 \mathrm{ml} / \mathrm{kg}$ for the doses of 2 and $4 \mathrm{mg} / \mathrm{kg}$ and in a volume of $4 \mathrm{ml} / \mathrm{kg}$ for the $8 \mathrm{mg} / \mathrm{kg}$ dose 
because of solubility constraint. Ethanol concentrations in THC solutions were between 2 and $4 \% \mathrm{v} / \mathrm{v}$. Corresponding amounts of ethanol were added to vehicle solutions. Heroin $\mathrm{HCl}$ (National Institute on Drug Abuse, Baltimore, MD, USA) was dissolved in distilled water and given by i.v. injection.

\section{Data Analysis}

Self-administration data were analyzed as number of responses $( \pm S E M)$ and number of injections per session $( \pm$ SEM) under the FR1 schedule. In addition, postreinforcement pauses (time between successive injections; \pm SEM) were analyzed under the FR1/variable-dose schedule. The break point (last ratio completed each session) was analyzed using a logarithmic transformation under the progressive-ratio schedule. Break point and post-reinforcement pause values for each rat at each dose were the average from two consecutive sessions. Data were analyzed using a two-way ANOVA for repeated measures followed, when appropriate, by post hoc Bonferroni's test. For acquisition of heroin self-administration experiments, the factors analyzed by two-way ANOVA were session number and pretreatment; for analysis of post-injection pauses under FR1, time between injections, and pretreatment; for FR1-VR selfadministration experiments, dose and pretreatment; for progressive-ratio experiments, dose, and pretreatment; for demand curves, price, and pretreatment. Changes were considered significant when $p<0.05$. Variability in patterns of responding under the FR1 schedule was analyzed using root mean square of successive differences (rMSSD; for details see Panlilio et al, 2003; Task Force of the European Society of Cardiology and the North American Society of Pacing and Electrophysiology, 1996; Tornatzky and Miczek, 2000). As the mean post-injection pauses differed between the THC- and vehicle-treated rats, rMSSD was scaled by dividing it by the mean post-injection pause for each rat (see Panlilio et al, 2003).

For non-normalized curves, prices were calculated by dividing the response requirement by the dose of heroin expressed as $\mu \mathrm{g} / \mathrm{kg}$. The normalization procedure (Hursh and Winger, 1995) transformed price to allow demand curves for different groups to be compared using the same origin. $P_{\max }$ is a measure of the elasticity of the demand function, indicating the price above which reinforced behavior no longer increases sufficiently to maintain the level of consumption. $O_{\max }$ is the number of responses per session at $P_{\max }$ and indicates the maximal amount of behavior that can be maintained by i.v. heroin injections as the price is varied. Demand curves were calculated using nonlinear regression following the normalization procedure described by Hursh and Winger (1995); see also Giordano et al (2001) and Winger et al (2002). This procedure determines the consumption of heroin at the lowest price for each dose, and then compares the consumption at higher prices to this value. A curve was fit to the normalized data using the equation $\log Q=\log (100)+B(X)-\left(A\left(10^{X}\right)\right) \log (e)$, where $Q$ is the mean level of consumption, $X$ is the unit price, $b$ is the initial slope of the demand curve at minimal price, and $a$ represents the acceleration or increase in slope. The regression was performed with the initial values of $a$ and $b$ set to 0.004 and -0.05 , respectively. The values of $a$ and $b$ obtained from the regression were used to calculate $P_{\max }$, the point where the theoretical demand curve switches from being inelastic to elastic, as $P_{\max }=(1+b) / a$. To determine whether demand curves differed between rats pre-exposed to THC and control rats pre-exposed to vehicle, $P_{\max }$ was calculated individually for each subject and a $t$-test was performed. Normalized response output functions were calculated in a manner similar to demand curves, but using the equation $\log R=\log (100)+(b+1) X-a \log (e)\left(10^{X}\right)$, where $R$ is the number of responses per session. Measures of reinforcing efficacy of i.v. heroin injections were indicated by the two variables, $P_{\max }$ and $O_{\max }$, which are traditionally obtained from the demand and response output curves (Bickel et al, 2000). Demand curves describe the relation between the level of heroin consumption (total drug intake per session) and price (FR value divided by dose per injection).

\section{RESULTS}

\section{Experiment One}

Acquisition of heroin self-administration under an FR1 schedule. Two rats in the THC group and three rats in the vehicle control group developed a blocked catheter during the acquisition of heroin self-administration and were excluded from the study. Eight of the 11 remaining animals pretreated with THC and eight of the 10 remaining animals pretreated with vehicle, acquired heroin self-administration within 10 experimental sessions. Rats that did not acquire heroin self-administration were not included in calculations and were excluded from the rest of the study.

Rats progressively increased the number of active nosepokes emitted (nose-pokes that resulted in heroin injections plus active nose-pokes emitted during the injection time and the time-out) and injections obtained until they both stabilized after about seven to eight sessions (Figure $1 \mathrm{a}, \mathrm{b}$ ). Statistical analysis revealed a significant session effect for both active nose-pokes $(\mathrm{F}(9,140)=15.69, p<0.0001)$ and injections $(\mathrm{F}(9,140)=18.82, p<0.0001)$. Rats pre-exposed to THC emitted significantly more active nose-pokes $(\mathrm{F}(1,9)=28.51, p<0.0001)$ and self-administered significantly more injections of heroin $(\mathrm{F}(1,9)=33.23, p<0.0001)$ compared to rats that were pre-exposed to vehicle (Figure 1). Also significant session-treatment interaction effects were found for both active nose-pokes $(\mathrm{F}(1,9)=2.52 ; p<0.01)$ and injections per session $((1,9)=2.29 ; p<0.01)$. These differences were still present at the end of the experiment, when rats were again tested under a simple FR1 schedule (after completing the variable-dose and progressive-ratio studies) for both active nose-pokes $(\mathrm{F}(2,42)=25.83$, $p<0.0001)$ and injections per session $(\mathrm{F}(2,42)=29.01$, $p<0.0001$ ) (Figure $1 \mathrm{a}, \mathrm{b}$; sessions $1 \mathrm{~b}, 2 \mathrm{~b}, 3 \mathrm{~b}$ ). In contrast, the number of inactive nose-pokes remained almost constant for all heroin self-administration sessions under the FR1 schedule and no differences were found between rats pre-exposed to THC or vehicle. Observing the event records of one rat pretreated with THC (Figure 2a) and one rat pretreated with vehicle (Figure $2 b$ ), and the frequency of post-injection pauses for all rats (Figure 2c) on day 10 of self-administration, it appears that a similar pattern of 

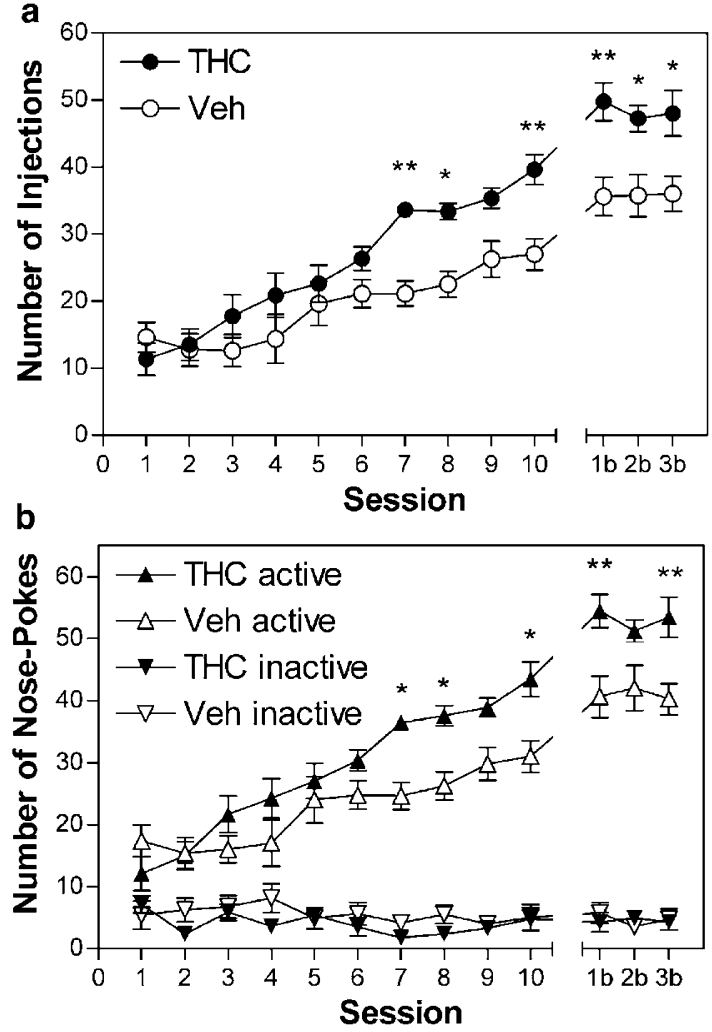

Figure I Acquisition of heroin self-administration ( $50 \mu \mathrm{g} / \mathrm{kg} /$ injection) under an FRI schedule in rats pre-exposed to THC or vehicle. Acquisition of heroin self-administration during a I0-day period at the beginning of the experiment (left) and self-administration of heroin at the end the experiment during a 3-day period (right). Data are expressed as mean $( \pm S E M)$ of the number of injections per session (a) and the number active and inactive nose-pokes per session (b) in rats pre-exposed to THC (filled symbols) or vehicle (empty symbols) $\left(N=8\right.$ per group). ${ }^{*} p<0.05$; ** $<<0.01$. Post hoc comparison with vehicle controls after significant two-way ANOVA main effect, Bonferroni test.

temporally regular self-administration had developed in the two groups, but rats pretreated with THC selfadministered heroin more frequently than rats pretreated with vehicle $(\mathrm{F}(1,15)=8.90, p<0.001)$. $\mathrm{rMSSD}$, a measure of the variability of sequential post-injection pauses, was determined for each rat during the final FR1 session prior to testing with the variable-dose schedule. The levels of variability (ie rMSSD scaled by the mean post-injection pauses) did not differ between the two groups, with mean ( \pm SEM) values of $1.33 \pm 0.17$ for the THC group and $1.54 \pm 0.13$ for the vehicle group. A $t$-test confirmed that this difference was not statistically significant $(p>0.35)$.

Heroin self-administration under an FR1/variabledose schedule. Post-reinforcement pauses were dose dependent $(\mathrm{F}(3,56)=23.49, p<0.0001)$ and were longer after higher doses of heroin. In rats pretreated with THC, post-reinforcement pauses were significantly shorter than in rats pretreated with vehicle $(\mathrm{F}(1,56)=13.51, p<0.001)$ (Figure 3). In other words, rats previously exposed to THC self-administered heroin at a significantly higher rate than control rats.
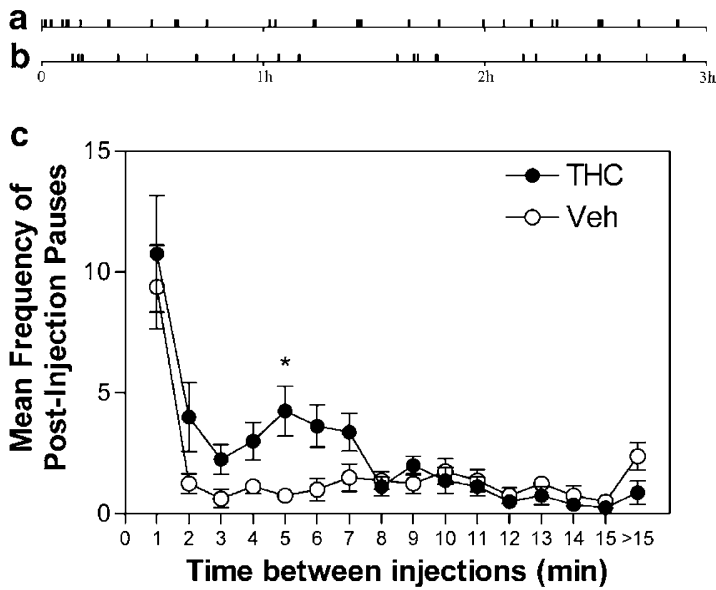

Figure 2 Pattern of self-administration of $50 \mu \mathrm{g} / \mathrm{kg}$ injections of heroin under an FRI schedule in rats pre-exposed to THC or vehicle. Representative event records of the last day (day 10) of acquisition of heroin self-administration of (a) one rat pre-exposed to THC or (b) to vehicle. (c) Mean frequency distribution of post-reinforcement pauses on the last day (day 10) of acquisition of heroin self-administration. Data in (c) are expressed as mean $( \pm S E M)$ of the number of heroin injections that occurred after each indicated post-reinforcement time expressed in minutes, in rats pre-exposed to THC (filled symbols) or vehicle (empty symbols) ( $N=8$ per group). $* 2<0.05$. Post hoc comparison with vehicle controls after significant two-way ANOVA main effect, Bonferroni test.

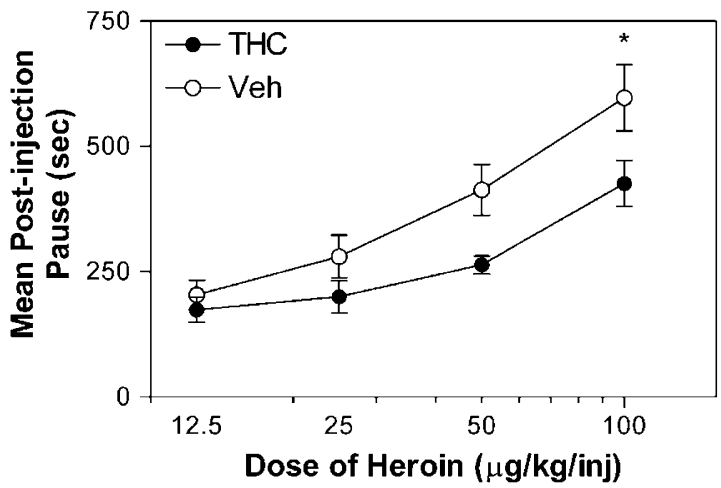

Figure 3 Self-administration of heroin under an FRI/variable-dose schedule in rats pre-exposed to THC or vehicle. Data are expressed as mean $( \pm$ SEM) of post-reinforcement pauses after delivery of different doses of heroin, in rats pre-exposed to THC (filled symbols) or vehicle (empty symbols) $\left(N=8\right.$ per group). ${ }^{*} p<0.05$. Post hoc comparison with vehicle controls after significant two-way ANOVA main effect, Bonferroni test.

Heroin self-administration under a progressive-ratio schedule. Rats readily learned to increase their response output to obtain heroin injections under the progressiveratio schedule. The heroin dose-response curve had an inverted U-shape as previously reported (Roberts and Bennett, 1993; Solinas et al, 2003), with the doses of 25 and $50 \mu \mathrm{g} / \mathrm{kg} /$ injection producing the highest break points. Heroin self-administration under the progressive-ratio schedule was dose-dependent, as measured by number of injections (step) $(\mathrm{F}(3,56)=3.46, p<0.05)$ (Figure $4 \mathrm{a})$, last ratio completed (Figure $4 \mathrm{~b}$ ) and heroin intake per session $(\mathrm{F}(3,56)=138.40, p<0.0001)$ (Figure $4 \mathrm{c})$. Importantly, no differences in the break point as measured by number of injections, last ratio completed or heroin intake per session 

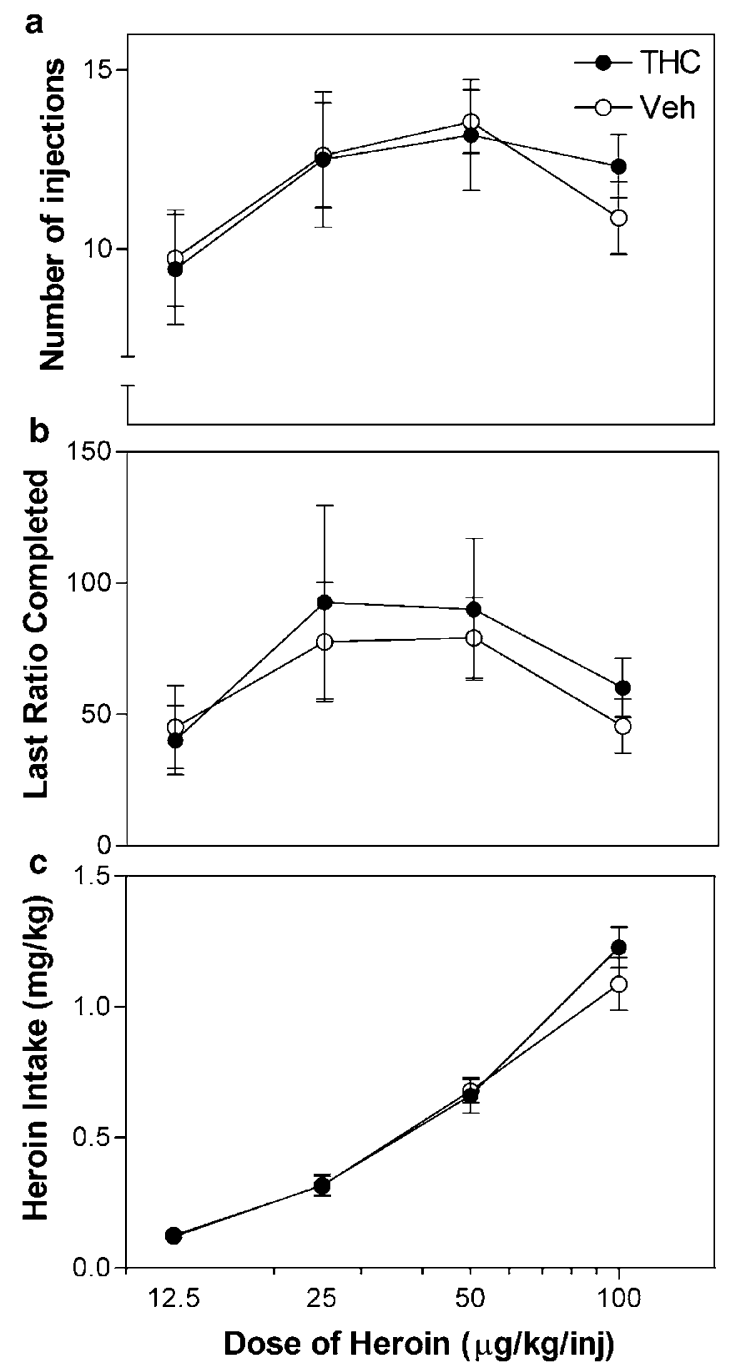

Figure 4 Self-administration of different doses of heroin under a progressive-ratio schedule in rats pre-exposed to THC or vehicle. Break points in rats pre-exposed to THC (filled symbols) or vehicle (empty symbols). Data are expressed as mean ( \pm SEM) of (a) the number of injections per session, (b) the last ratio completed, and (c) heroin intake in $\mathrm{mg} / \mathrm{kg}$ per session ( $N=8$ per group).

were found between rats pre-exposed to THC and rats preexposed to vehicle (Figure $4 \mathrm{a}-\mathrm{c}$ ).

\section{Experiment Two}

Heroin consumption as a function of price under $F R$ schedules. One rat in the THC group and two rats in the vehicle control group developed a blocked catheter during the acquisition of heroin self-administration and were excluded from the study. One rat pre-exposed to THC and one rat pre-exposed to vehicle did not acquire heroin selfadministration (ie did not obtain more than 10 injections per sessions in any experimental session) even though they received priming injections of heroin. All the other rats acquired stable heroin self-administration within eight to 14 experimental sessions. Two rats pre-exposed to THC and three rats pre-exposed to vehicle developed a blocked catheter in an advanced phase of the experiment and experimental sessions were conducted after a second catheter was implanted, as described in the Materials and methods section. Figure 5 shows (a) the number of responses by rats and (b) the heroin intake at different doses when the FR response requirement was increased. At the initial FR1 response requirement and at injection doses of 50 and $100 \mu \mathrm{g} /$ $\mathrm{kg}$, rats pretreated with THC earned significantly more heroin injections than control rats-pretreated with vehicle (Student's $t$-test; $p<0.05$; inserted panels in Figure 5a). Again, these differences were due to the fact that rats pretreated with THC self-administered heroin injections more frequently than control rats pretreated with vehicle, as demonstrated by analysis of post-injection pauses $(\mathrm{F}(1,15)=6.92, p<0.05$ at the heroin dose of $50 \mu \mathrm{g} / \mathrm{kg} /$ injection; $\mathrm{F}(1,15)=5.54, p<0.05$ at the heroin dose of $100 \mu \mathrm{g} / \mathrm{kg} /$ injection) (data not shown). Also consistent with results of Experiment one, variability of response patterns (as measured by rMSSD scaled by the mean post-injection pause) did not differ between the groups when measured under the FR1 schedule at heroin doses of either 50 or $100 \mu \mathrm{g} / \mathrm{kg} /$ injection ( $p$ 's $>0.53$ ). At these doses, when the FR response requirement was increased, the number of responses increased monotonically for most rats, but some stopped responding after the first few injections. No differences were found between rats pre-exposed to THC and control rats pre-exposed to vehicle. At heroin doses lower than $50 \mu \mathrm{g} / \mathrm{kg} /$ injection, at the FR1 response requirement, rats pre-exposed to THC self-administered more injections than rats pre-exposed to vehicle, but these differences were not statistically significant. At the heroin dose of $25 \mu \mathrm{g} / \mathrm{kg} /$ injection, when the FR response requirement was increased, some rats increased the number of responses emitted and reached the highest level measured in this experiment for an FR value of 15; on the other hand, other rats stopped responding after the first few injections. When the FR response requirement was increased to 30 , most rats stopped responding and thus the curve assumed a negative slope. No differences were found between THC- and vehiclepre-exposed rats. At the lowest heroin dose tested, $12.5 \mu \mathrm{g} /$ $\mathrm{kg} /$ injection, when the FR requirement was increased from 1 to 5 , rats increased the number of responses emitted, but further increases in FR response requirement resulted in decreases in the number of responses emitted in most animals. Heroin intake decreased monotonically as the FR response requirement was increased at each heroin dose (Figure 5b).

Demand and response output curves (Figure 6a,b) were calculated based on response requirements (FR value) and the unit dose of heroin $(\mu \mathrm{g} / \mathrm{kg})$. At the lowest prices (ie when the FR value was low and the dose per injection was high), the curves again confirmed that the THC-preexposed to rats consumed more heroin (Figure 6a) and responded at higher rates (Figure $6 \mathrm{~b}$ ) than vehicle controls. However, as the price was increased, the two groups showed almost identical levels of consumption and response output.

Normalized demand curves (Figure 6c,d) provided estimates of $P_{\max }$, the highest price at which animals maintained a relatively constant heroin intake (consumption) and the price at which they showed the highest response output (estimated as $O_{\max }$ ). The goodness of fit for the demand and response output curves to the averaged data was excellent; $R^{2}$ values were 0.945 and 0.997 for the THC-pre-exposed group and 0.958 and 0.933 for the vehicle-pre-exposed group. Consistent with other 
a
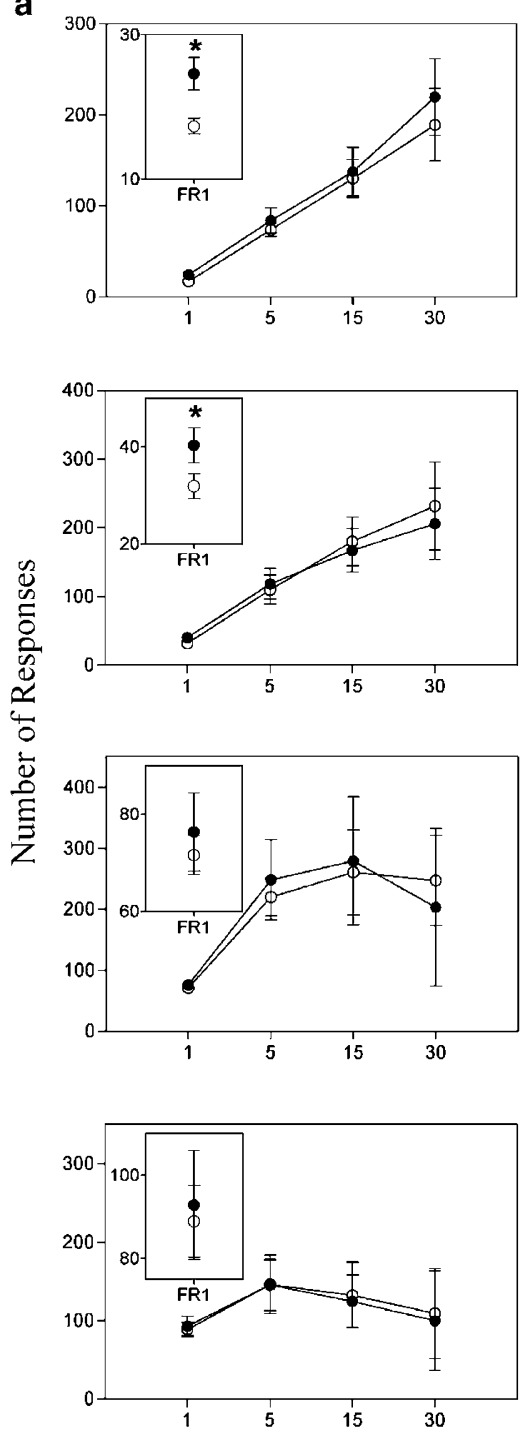

Her 100

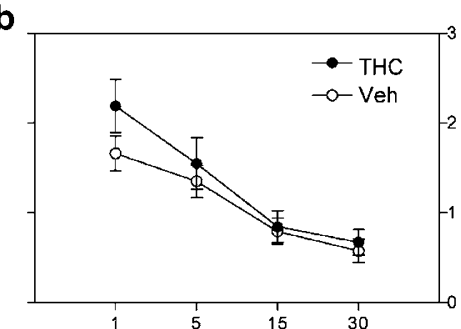

Her 50

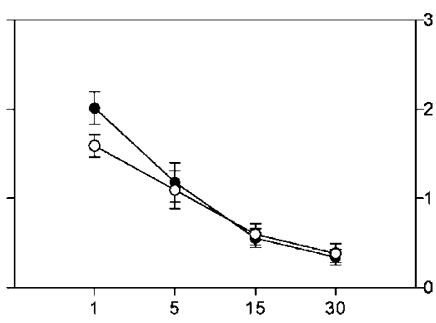

Her 25

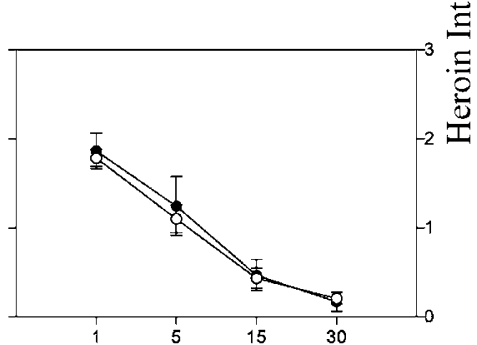

Her 12.5

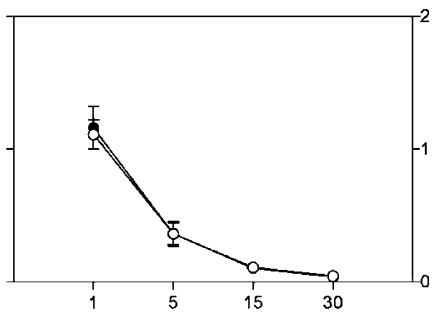

FR Requirement

Figure 5 Self-administration of different doses of heroin under FR schedules with different response requirements in rats pre-exposed to THC or vehicle. Number of responses (a) and heroin intake (b) as a function of FR values at different doses of heroin in rats pre-exposed to THC (filled symbols) or vehicle (empty symbols) ( $N=13$ per group). Inserted panels magnify the ordinates (number of responses) to allow visualization of differences that occurred under the FRI condition. $* p<0.05$. Student's t-test.

observations in behavioral economics studies, we found that heroin consumption was relatively constant at low normalized prices but decreased abruptly at high prices (Figure 6c). Accordingly, the number of responses emitted increased as the normalized price increased until the price became too high and an abrupt drop in responding was observed (Figure 6d). Consistent with the results of progressive-ratio testing in experiment one, the normalized demand and response output curves were quite similar for the THC and vehicle pre-exposed groups, and there was no significant difference in $P_{\max }$ between the groups $(p>0.39)$.

\section{DISCUSSION}

In this study, rats passively pre-exposed to either THC or vehicle subsequently learned to self-administer heroin. No differences were found in the percentage of rats acquiring heroin self-administration behavior, but rats pre-exposed to THC developed higher heroin intakes and showed reduced post-reinforcement pauses across a range of unit doses. When the reinforcing effectiveness of heroin was directly measured using a progressive-ratio schedule, however, no differences were found between rats pre-exposed to THC and control rats pre-exposed to vehicle. In a subsequent experiment, rats pre-exposed to THC again self-administered more heroin injections than control rats pre-exposed to vehicle, when responding on an FR1 schedule for high doses of heroin. However, no differences were found between rats pre-exposed to THC or vehicle when the price of heroin (response requirement divided by dose) was changed over successive sessions. When, demand curves, relating price of heroin to consumption, and response output curves, relating price of heroin to responding, were 

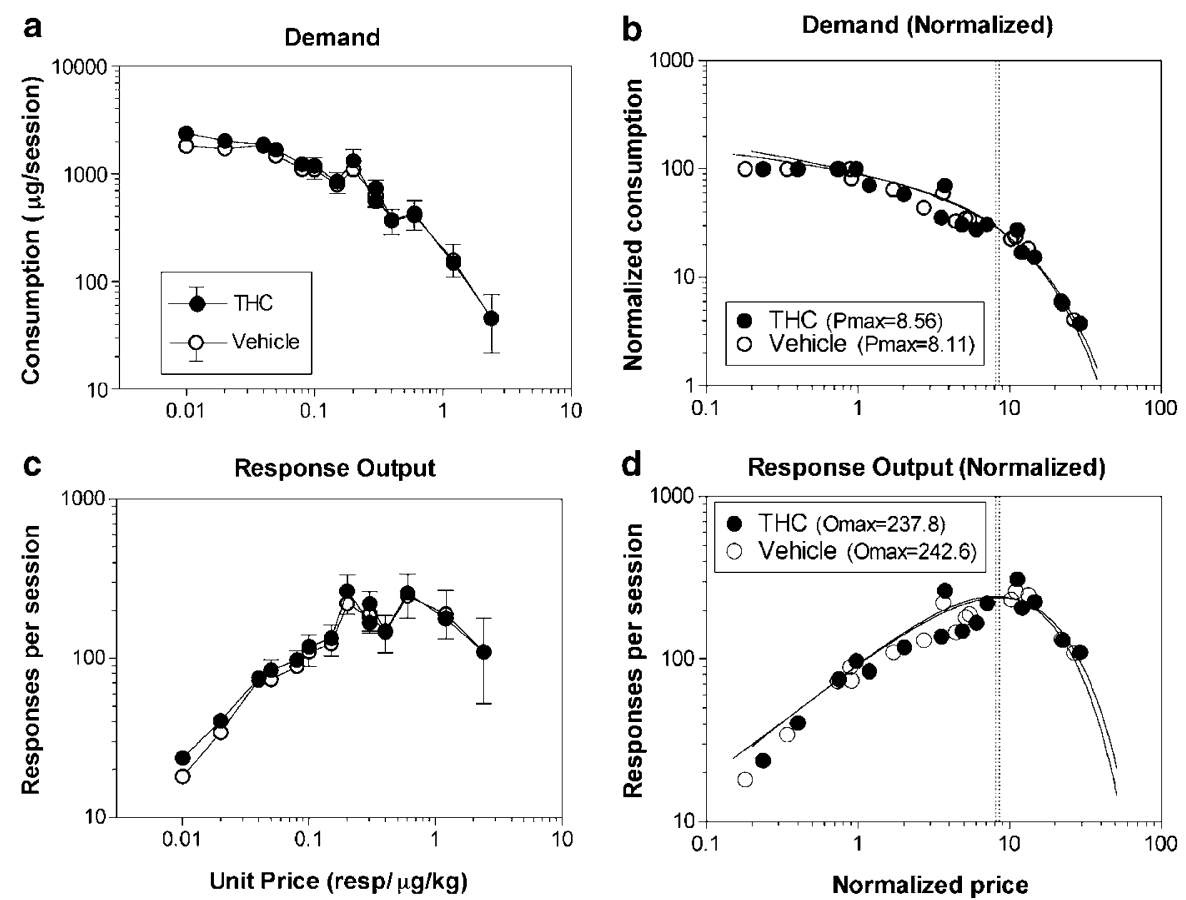

Figure 6 Demand and response output curves for heroin in rats pre-exposed to THC or vehicle. (a) Heroin intake and (b) number of responses as a function of heroin prices (FR value/unit dose in $\mu \mathrm{g} / \mathrm{kg}$ ) in rats pre-exposed to THC (filled symbols) or vehicle (empty symbols). (c) Normalized heroin intake and $(\mathrm{d})$ number of responses as a function of normalized heroin prices ( $N=13$ per group) in rats pre-exposed to THC (filled symbols) or vehicle (empty symbols). Vertical dotted lines indicate the price at which $P_{\max }$ and $O_{\max }$ occurred.

plotted, using a behavioral economics framework (Bickel et al, 2000), there was no significant difference between rats pre-exposed to THC and those pre-exposed to vehicle in either the $P_{\max }$ value (the price above which consumption decreased) or the $O_{\max }$ value (the price at which maximal responding was maintained), confirming that the reinforcing effectiveness of heroin was unchanged by THC preexposure.

Heroin self-administration at a dose of $50 \mu \mathrm{g} / \mathrm{kg} /$ injection was acquired similarly in rats pre-exposed to THC or vehicle. The percentage of rats that acquired heroin selfadministration within 10 sessions was, respectively, 72.7 and $80 \%$ (ie eight out of 11 and eight out of 10 rats, respectively). This level of acquisition is slightly higher than the one reported by van Ree et al (1978), when the dose of $50 \mu \mathrm{g} / \mathrm{kg} /$ injection was found to be the $\mathrm{ED}_{50}$ for acquisition of heroin self-administration. In that study, $\mathrm{ED}_{50}$ was calculated with a regression analysis from acquisition data at higher doses, and other methodological differences (food restricted $v s$ ad libitum food, nose-poke $v s$ lever pressing responding) could have determined these differences.

In acquisition studies, near threshold doses of drugs are usually used to magnify differences between groups in the percentage of animals acquiring arbitrary criteria of selfadministration (Campbell and Carroll, 2000). The percentage of animals that acquire self-administration behavior and the speed at which this acquisition occurs are used as a measure of reinforcing efficacies of drugs. Several factors have been shown to modulate acquisition of self-administration behavior, such as genetics, gender, environmental factors, stress, and other individual differences (Campbell and Carroll, 2000). Pharmacological treatments and drug exposure also can influence acquisition. For example, rats exposed to caffeine acquire nicotine self-administration faster than rats exposed to water (Shoaib et al, 1999). Thus, it is possible that rats pre-exposed to THC or vehicle might have differed in their subsequent acquisition of heroin selfadministration behavior if lower training doses had been used. However the finding in the present study, that the reinforcing efficacy of heroin as measured by percentage of animals acquiring self-administration did not differ in rats pre-exposed to THC or vehicle, is strengthened by the fact that when reinforcing efficacy was assessed using progressive-ratio schedules and behavioral economics analysis, no differences were again found between groups.

Although THC pre-exposure did not affect the percentage of rats that acquired heroin self-administration, rats preexposed to THC showed a higher intake of heroin under the FR1 schedule and shorter post-reinforcement pauses under an FR1/variable-dose schedule. This was also true in a second experiment when baseline responding under an FR1 schedule was evaluated at the same $50 \mu \mathrm{g} / \mathrm{kg}$, or at a higher $100 \mu \mathrm{g} / \mathrm{kg}$, heroin injection dose. This suggests that some changes in the pharmacological effects of heroin had taken place. These changes are likely to be the same as those responsible for the behavioral sensitization (and crosssensitization) found after repeated administration of cannabinoid CB1 receptor agonists (Cadoni et al, 2001; Lamarque et al, 2001; Pontieri et al, 2001; Rubino et al, 2001; Norwood et al, 2003). Tolerance to the depressant effects of heroin could account for the differences found under FR1 schedules. It has been shown that repeated administration of the cannabinoid $\mathrm{CB} 1$ receptor agonist Win 55-212, sensitizes the locomotor response to heroin challenge and that this effect is due, at least in part, to tolerance that develops to the depressant effects of heroin 
(Pontieri et al, 2001). It has also been shown that a protocol of pre-exposure to the cannabinoid agonist CP-55,940 increases not only the motor response to a morphine administration but also morphine self-administration (Norwood et al, 2003). Although the interpretation of that study was tentative for various reasons, including the fact that ' $a$ clear acquisition curve was not present across self-administration sessions' (Norwood et al, 2003), those results support the present findings.

While clear and persistent differences between rats preexposed to THC or vehicle were found under the FR1 schedules, no differences were found under the progressiveratio schedule. Similar discrepancies have been often found between the effects of certain treatments on measures of drug intake regulation and drug reinforcement efficacy in many previous studies (see Arnold and Roberts, 1997 for a review), suggesting that these two paradigms measure distinct aspects of reinforcement. For example, while exposure to a long $(72 \mathrm{~h})$ session of cocaine self-administration followed by 7 days of withdrawal results in an increase in cocaine selfadministration under an FR1 schedule and no change under a progressive-ratio schedule, exposure to multiple limited intake sessions of cocaine followed by 7 days withdrawal results in an increase in the break point under a progressiveratio schedule but no change in cocaine self-administration under an FR1 schedule (Morgan et al, 2002). Also, we previously found that the cannabinoid antagonist SR-141716 markedly decreased heroin self-administration under a progressive-ratio schedule, had no effects on self-administration of high doses of heroin under an FR1 schedule, and produced a small decrease in self-administration of low doses of heroin under an FR1 schedule (Solinas et al, 2003).

It has been suggested (Mendrek et al, 1998) that FR and progressive-ratio schedules measure two different components of reward (liking and wanting) proposed in the incentive sensitization theory of Robinson and Berridge (1993). Thus, the progressive-ratio schedule would be a more appropriate measure for the preparatory, seeking component of reward (wanting) while the FR1 schedule would be a more appropriate measure for the consummatory, taking component of reward (liking). In this context, THC exposure in the present study appeared to produce a change in the consummatory component of heroin selfadministration without affecting the incentive value of heroin. Regardless of the nature of the reinforcement aspects measured by FR1 and progressive-ratio schedules, we found that only FR1 self-administration of high heroin doses was affected by pre-exposure to THC.

Similar to our findings with the progressive-ratio schedule, when demand curves were calculated for heroin self-administration using a wide range of heroin prices, rats pre-exposed to THC and control rats pre-exposed to vehicle did not differ. This was true whether the data were expressed in absolute price (responses $/ \mu \mathrm{g} / \mathrm{kg}$ ) or normalized price with the origin of the curves equalized. $P_{\max }$ and $O_{\max }$ values were also almost identical in the two groups, confirming that they valued heroin similarly. This is in agreement with previous observations that the behavioral economics analysis and the progressive-ratio procedures produce qualitatively similar results (Bickel et al, 2000; Rodefer and Carroll, 1996, 1997). In fact, break point would measure both maximal responding and the point at which responding ceases, while $P_{\max }$ and $O_{\max }$ would measure the point at which behavior peaks. On the other hand, in some instances, the use of FR schedules to calculate demand curves can be a more sensitive measure of reinforcing efficacy than progressive-ratio schedules (Rodefer and Carroll, 1996). This could be due to the high drug intake that occurs during early phases of progressive-ratio sessions, when relatively few responses are needed to deliver relatively high doses of drug. Thus, direct drug effects could interfere with subsequent performance and/or motivation for drug self-administration. The fact that both progressive-ratio and behavioral economics analysis demonstrate no difference between THC and vehicle preexposed to rats strongly suggests that motivation for heroin self-administration was not altered by THC exposure.

The interpretation of increases in heroin self-administration in rats pre-exposed to heroin observed under the FR1 schedules in this study remains uncertain. Decreases in the number of injections under FR schedules are usually interpreted as an increase in the effects of the drug (ie mimic the effects of an increase in the unit dose) while increases in the number of injections under FR schedules usually are interpreted as a decrease in the effects of the drug (ie mimic the effects of a decrease in the unit dose). In this context, THC pre-exposure seems to have reduced the sensitivity to heroin's effects or, at least, to have shortened the duration of heroin's effects, as suggested by the FR1/variable-dose results.

Animals typically self-administer drugs at regularly spaced intervals under FR1 schedules (Yokel and Pickens, 1974; Dougherty and Pickens, 1976; Pickens et al, 1981; Wise et al, 1995a,b; Lynch et al, 1998). However, under certain conditions (eg exposure to prolonged periods of drug availability), this pattern of intake may be dysregulated, leading to an escalation of drug use (Ahmed et al, 2000; Ahmed and Koob, 1998; Bozarth and Wise, 1985; Tornatzky and Miczek, 2000). To determine whether a loss of highly patterned self-administration behavior was responsible for the increased self-administration of heroin observed here in rats pre-exposed to THC, the regularity of response patterns was formally analyzed (for details of this analysis, see Panlilio et al, 2003). The fact that patterns of self-administration were similar in both groups suggests that intake of heroin did not become dysregulated in the rats pre-exposed to THC.

The mechanism(s) underlying behavioral cross-sensitization between opioids and cannabinoids and, likely, the increase in opiate intake after cannabinoid pre-exposure in self-administration studies (Norwood et al, 2003, and the present study) has not been elucidated. Even though pharmacokinetic changes in the distribution, metabolism, and clearance of heroin cannot be ruled out, pharmacodynamic changes are more likely to be responsible for these effects. Changes in receptor number, second messenger cascade activation, and neurotransmitter levels and release have been described after chronic administration of THC and could account for the behavioral effects observed. For example, exposure to a regimen of THC that produces sensitization has been shown to increase the number of cannabinoid $\mathrm{CB} 1$ receptors in the cerebellum and to increase G-protein activation in the caudate-putamen and cerebellum (Rubino et al, 2003). Chronic administration of THC has also been shown to produce changes in brain levels 
of met-enkephalin, substance-P, $\beta$-endorphin and serotonin (Miczek and Dixit, 1980; Kumar et al, 1990) that could underlie differences in sensitivity to heroin between rats pre-exposed to THC and control rats pre-exposed to only vehicle. Also, THC is reported to produce anxiogenic effects at high doses (Chaperon and Thiebot, 1999). Given that stressors can alter opiate self-administration (Lu et al, 2003 for a review), it is also possible that anxiogenic effects of the high doses of THC administered on the last day of exposure, could have contributed to the increased self-administration of heroin by rats pre-exposed to THC under the FR1 schedule. On the other hand, Shaham and Stewart (1994) found that exposure to a stressor such as foot-shock increases heroin break point under a progressive-ratio schedule but had no effects on heroin intake under low FR schedules. Thus, it is unlikely that stress contributed to the present results since rats pre-exposed to THC had higher heroin intakes than control rats pre-exposed only to vehicle under low FR schedules but break points, $P_{\max }$ and $O_{\max }$ were not different in the two groups. In any case, it is difficult to extrapolate conclusions from such comparisons, given that different stressors have been shown to influence self-administration behaviors in different ways ( $\mathrm{Lu}$ et al, 2003 for a review).

In conclusion, in this study we found that heroin selfadministration was altered in rats given prior exposure to the main psychoactive ingredient in cannabis, $\Delta-9$-THC, at a level of exposure known to produce behavioral sensitization to THC and cross-sensitization to morphine (Cadoni et al, 2001). However, these changes appear to reflect tolerance to the pharmacological effects of heroin that limit responding rather than an increase in heroin's reinforcing efficacy. Altogether, our findings do not support the assumption that exposure to cannabis would make people more vulnerable to the direct reinforcing effects of heroin. Further studies are needed to determine whether exposure to other protocols of THC pre-exposure could produce changes in the reinforcing efficacy of heroin. For example, it might be important to study the effects of a longer exposure to lower doses of THC to better mimic typical cannabis exposure in humans. Also, studying the effects of THC preexposure in rat strains such as Lewis and Fischer rats that appear to show higher or lower sensitivity to THC's positive effects than Sprague-Dawley rats, as measured by lowering of brain stimulation reward (Lepore et al, 1996) and by increases in dopamine release in the nucleus accumbens (Chen et al, 1991), might yield different results. It should be noted, however, that we have recently demonstrated both intracranial THC self-administration under an FR1 schedule and conditioned place preferences with intracranial THC in Sprague-Dawley rats (Zangen et al, 2002), indicating their suitability for the present experiments. Although further studies are needed, the present findings offer no support for the hypothesis that changes in the reinforcing efficacy of heroin account for the epidemiological data supporting the gateway drug hypothesis for early cannabis exposure.

\section{ACKNOWLEDGEMENT}

We thank Dr G Winger for assistance in the calculation of demand and response output curves.

\section{REFERENCES}

Ahmed SH, Koob GF (1998). Transition from moderate to excessive drug intake: change in hedonic set point. Science 282: 298-300.

Ahmed SH, Walker JR, Koob GF (2000). Persistent increase in the motivation to take heroin in rats with a history of drug escalation. Neuropsychopharmacology 22: 413-421.

Arnold JM, Roberts DC (1997). A critique of fixed and progressive ratio schedules used to examine the neural substrates of drug reinforcement. Pharmacol Biochem Behav 57: 441-447.

Bachman JG, Johnson LD, O'Malley PM (1998). Explaining recent increases in students' marijuana use: impacts of perceived risks and disapproval, 1976 through 1996. Am J Public Health 88: 887-892.

Bickel WK, Marsch LA, Carroll ME (2000). Deconstructing relative reinforcing efficacy and situating the measures of pharmacological reinforcement with behavioral economics: a theoretical proposal. Psychopharmacology (Berl) 153: 44-56.

Bozarth MA, Wise RA (1985). Toxicity associated with long-term intravenous heroin and cocaine self-administration in the rat. J Am Med Assoc 254: 81-83.

Cadoni C, Pisanu A, Solinas M, Acquas E, Di Chiara G (2001). Behavioural sensitization after repeated exposure to Delta 9tetrahydrocannabinol and cross-sensitization with morphine. Psychopharmacology (Berl) 158: 259-266.

Campbell UC, Carroll ME (2000). Acquisition of drug selfadministration: environmental and pharmacological interventions. Exp Clin Psychopharmacol 8: 312-325.

Chaperon F, Thiebot MH (1999). Behavioral effects of cannabinoid agents in animals. Crit Rev Neurobiol 13: 243-281.

Chen JP, Paredes W, Lowinson JH, Gardner EL (1991). Strainspecific facilitation of dopamine efflux by delta 9-tetrahydrocannabinol in the nucleus accumbens of rat: an in vivo microdialysis study. Neurosci Lett 129: 136-180.

Dougherty J, Pickens R (1976). Pharmacokinetics of intravenous cocaine self-injection. In: Mule SJ (ed). Cocaine: Chemical, Biological, Clinical, Social and Treatment Aspect. CRC Press: Cleveland. pp 105-120.

Giordano LA, Bickel WK, Shahan TA, Badger GJ (2001). Behavioral economics of human drug self-administration: progressive ratio versus random sequences of response requirements. Behav Pharmacol 12: 343-347.

Hursh SR (1991). Behavioral economics of drug self-administration and drug abuse policy. J Exp Anal Behav 56: 377-393.

Hursh SR, Winger G (1995). Normalized demand for drugs and other reinforcers. J Exp Anal Behav 64: 373-384.

Kandel DB (2003). Does marijuana use cause the use of other drugs? J Am Med Assoc 289: 482-483.

Kandel DB, Yamaguchi K, Chen K (1992). Stages of progression in drug involvement from adolescence to adulthood: further evidence for the gateway theory. J Stud Alcohol 53: 447-457.

Kumar AM, Haney M, Becker T, Thompson ML, Kream RM, Miczek KA (1990). Effect of early exposure to delta-9tetrahydrocannabinol on the levels of opioid peptides, gonadotropin-releasing hormone and substance $\mathrm{P}$ in the adult male rat brain. Brain Res 525: 78-83.

Lamarque S, Taghzouti K, Simon H (2001). Chronic treatment with Delta(9)-tetrahydrocannabinol enhances the locomotor response to amphetamine and heroin. Implications for vulnerability to drug addiction. Neuropharmacology 41: 118-129.

Lepore M, Liu X, Savage V, Matalon D, Gardner EL (1996). Genetic differences in delta 9-tetrahydrocannabinol-induced facilitation of brain stimulation reward as measured by a rate-frequency curve-shift electrical brain stimulation paradigm in three different rat strains. Life Sci 58: PL365-PL372.

Lu L, Shepard JD, Scott Hall F, Shaham Y (2003). Effect of environmental stressors on opiate and psychostimulant 
reinforcement, reinstatement and discrimination in rats: a review. Neurosci Biobehav Rev 27: 457-491.

Lynch WJ, LaBounty LP, Carroll ME (1998). A novel paradigm to investigate regulation of drug intake in rats self-administering cocaine or heroin intravenously. Exp Clin Psychopharmacol 6: $22-31$.

Lynskey MT, Heath AC, Bucholz KK, Slutske WS, Madden PA, Nelson EC et al (2003). Escalation of drug use in early-onset cannabis users vs co-twin controls. J Am Med Assoc 289: 427-433.

Mendrek A, Blaha CD, Phillips AG (1998). Pre-exposure of rats to amphetamine sensitizes self-administration of this drug under a progressive ratio schedule. Psychopharmacology (Berl) 135: 416-422.

Miczek KA, Dixit BN (1980). Behavioral and biochemical effects of chronic delta 9-tetrahydrocannabinol in rats. Psychopharmacology (Berl) 67: 195-202.

Morgan D, Brebner K, Lynch WJ, Roberts DC (2002). Increases in the reinforcing efficacy of cocaine after particular histories of reinforcement. Behav Pharmacol 13: 389-396.

Norwood CS, Cornish JL, Mallet PE, McGregor IS (2003). Preexposure to the cannabinoid receptor agonist CP 55,940 enhances morphine behavioral sensitization and alters morphine self- administration in Lewis rats. Eur J Pharmacol 465: 105-114.

Panlilio LV, Katz JL, Pickens RW, Schindler CW (2003). Variability of drug self-administration in rats. Psychopharmacology (Berl) 167: 9-19.

Pickens R, Muchow D, DeNoble V (1981). Methohexital-reinforced responding in rats: effects of fixed ratio size and injection dose. $J$ Pharmacol Exp Ther 216: 205-209.

Pontieri FE, Monnazzi P, Scontrini A, Buttarelli FR, Patacchioli FR (2001). Behavioral sensitization to heroin by cannabinoid pretreatment in the rat. Eur J Pharmacol 421: R1-R3.

Reid A, Lynskey M, Copeland J (2000). Cannabis use among Australian adolescents: findings of the 1998 National Drug Strategy Household Survey. Aust NZ J Public Health 24: 596-602.

Roberts DC, Bennett SA (1993). Heroin self-administration in rats under a progressive ratio schedule of reinforcement. Psychopharmacology (Berl) 111: 215-218.

Robinson TE, Berridge KC (1993). The neural basis of drug craving: an incentive-sensitization theory of addiction. Brain Res Brain Res Rev 18: 247-291.

Rodefer JS, Carroll ME (1996). Progressive ratio and behavioral economic evaluation of the reinforcing efficacy of orally delivered phencyclidine and ethanol in monkeys: effects of feeding conditions. Psychopharmacology (Berl) 128: 265-273.

Rodefer JS, Carroll ME (1997). A comparison of progressive ratio schedules versus behavioral economic measures: effect of an alternative reinforcer on the reinforcing efficacy of phencyclidine. Psychopharmacology (Berl) 132: 95-103.
Rubino T, Vigano D, Massi P, Parolaro D (2001). The psychoactive ingredient of marijuana induces behavioural sensitization. Eur J Neurosci 14: 884-886.

Rubino T, Vigano D, Massi P, Parolaro D (2003). Cellular mechanisms of Delta 9-tetrahydrocannabinol behavioural sensitization. Eur J Neurosci 17: 325-330.

Shaham Y, Stewart J (1994). Exposure to mild stress enhances the reinforcing efficacy of intravenous heroin self-administration in rats. Psychopharmacology (Berl) 114: 523-527.

Shoaib M, Swanner LS, Yasar S, Goldberg SR (1999). Chronic caffeine exposure potentiates nicotine self-administration in rats. Psychopharmacology (Berl) 142: 327-333.

Solinas M, Panlilio LV, Antoniou K, Pappas LA, Goldberg SR (2003). The cannabinoid CB1 antagonist $N$-piperidinyl-5(4-chlorophenyl)-1-(2,4-dichlorophenyl) -4-methylpyrazole-3carboxamide (SR-141716A) differentially alters the reinforcing effects of heroin under continuous reinforcement, fixed ratio, and progressive ratio schedules of drug self-administration in rats. J Pharmacol Exp Ther 306: 93-102.

Task Force of the European Society of Cardiology and the North American Society of Pacing and Electrophysiology (1996). Heart rate variability: standards of measurement, physiological interpretation, and clinical use. Eur Heart J 17: 354-381.

Tornatzky W, Miczek KA (2000). Cocaine self-administration 'binges': transition from behavioral and autonomic regulation toward homeostatic dysregulation in rats. Psychopharmacology (Berl) 148: 289-298.

van Ree JM, Slangen JL, de Wied D (1978). Intravenous selfadministration of drugs in rats. J Pharmacol Exp Ther 204: 547-557.

Winger G, Hursh SR, Casey KL, Woods JH (2002). Relative reinforcing strength of three $N$-methyl-D-aspartate antagonists with different onsets of action. J Pharmacol Exp Ther 301: 690-697.

Wise RA, Leone P, Rivest R, Leeb K (1995a). Elevations of nucleus accumbens dopamine and DOPAC levels during intravenous heroin self-administration. Synapse 21: 140-148.

Wise RA, Newton P, Leeb K, Burnette B, Pocock D, Justice Jr JB (1995b). Fluctuations in nucleus accumbens dopamine concentration during intravenous cocaine self-administration in rats. Psychopharmacology (Berl) 120: 10-20.

Yokel RA, Pickens RW (1974). Drug level of $d$ - and $l$-amphetamine during intravenous self-administration. Psychopharmacologia 34: $255-264$

Zangen A, Solinas M, Goldberg SR, Wise RA (2002). Intracranial self-administration and psychomotor stimulant effects of delta-9-tetrahydrocannabinol. Society for Neuroscience Meeting Program No. 900.1. 2002 Abstract Viewer/Itinerary Planner, Society for Neuroscience, Washington, DC, 2002, online. 